\title{
Gas Production from Methane Hydrate in a Pilot-Scale Hydrate Simulator Using the Huff and Puff Method by Experimental and Numerical Studies
}

\author{
Bo Li, ${ }^{\dagger}$ Gang Li, ${ }^{\dagger}$ Xiao-Sen Li, ${ }^{*}{ }^{\dagger}$ Qing-Ping Li, ${ }^{\dagger}$ Bo Yang, ${ }^{\dagger}$ Yu Zhang, ${ }^{\dagger}$ and Zhao-Yang Chen ${ }^{\dagger}$ \\ ${ }^{\dagger}$ Key Laboratory of Renewable Energy and Gas Hydrate, Guangzhou Institute of Energy Conversion, Chinese Academy of Sciences, \\ Guangzhou 510640, China
}

\begin{abstract}
A novel three-dimensional 117.8-L pressure vessel, which is called a Pilot-Scale Hydrate Simulator (PHS), is developed to investigate the gas production performance from hydrate-bearing porous media using the huff and puff method through both experimental and numerical simulations. The methane gas and deionized water are injected into the pressure vessel to synthesize methane hydrate. The grain sizes of the quartz sand in the vessel are between 300 and $450 \mu \mathrm{m}$. The huff and puff stages, including the injection, the soaking, and the production, are employed for hydrate dissociation. A single vertical well at the axis of the PHS is used as the injection and production well. The whole experiment consists of 15 huff and puff cycles. The numerical simulation results agree well with the experiment. Both the experimental and numerical simulation results indicate that the injected water is mainly restricted around the well during the injection stage. The system pressure fluctuates regularly in each cycle, and the secondary hydrate is formed under the pressurization effect caused by the hot water injection in the injection stage. The gas production rate maintains approximately stable in a relatively long period. The sensitivity analysis indicates that the gas production can be enhanced with high intrinsic permeability of the deposit or by raising the temperature of the injected hot water. The mass of the water produced in each cycle has little difference and is manageable when using the huff and puff method.
\end{abstract}

\section{INTRODUCTION}

Natural gas hydrates (NGH) are crystalline compounds in which small guest molecules (such as $\mathrm{CH}_{4}, \mathrm{CO}_{2}, \mathrm{H}_{2} \mathrm{~S}$, etc.) occupy the host lattices formed by water molecules. The majority of naturally occurring gas hydrates contain $\mathrm{CH}_{4}$, and the amount of natural gases trapped in gas hydrates is estimated to be huge. Recent seismic explorations and geological researches show that natural gas hydrates exist widely in marine sediments and permafrost areas where the necessary conditions of low temperature and high pressure exist for hydrate stability. ${ }^{1}$ It is thought to be a potential strategic energy resource that can replace the known conventional fossil fuel resources in the future. ${ }^{2}$

Decomposition of gas hydrate can be induced by shifting the thermodynamic equilibrium conditions. The following methods have been proposed: (1) depressurization, ${ }^{3-5}$ in which the deposit pressure is set to be lower than the hydration pressure at the prevailing temperature; (2) thermal stimulation, ${ }^{6-11}$ in which hot water or heat is injected into the deposit to raise the temperature above the dissociation temperature; (3) thermodynamic inhibitor injection, ${ }^{12-14}$ in which the hydrate pressure-temperature equilibrium conditions are shifted by the use of chemicals, such as salts and alcohols. Another production method involves replacement of $\mathrm{CH}_{4}$ in the hydrate by another hydrate-forming gas (e.g., $\mathrm{CO}_{2}$ ) of which the equilibrium reaction conditions are more favorable. ${ }^{15,16}$

Recent studies have shown that gas production can be enhanced when depressurization is used in conjunction with thermal stimulation by hot water, hot brine, or steam injection with the vertical well. ${ }^{17,18}$ The huff and puff method, also known as the cyclic steam stimulation (CSS), was accidentally discovered by the Shell Oil Company in 1960 and is widely used in the oil industry. ${ }^{19,20}$ When used in gas production from hydrates, it is a special form of the combination of depressurization and thermal stimulation methods.

Recent numerical simulations have employed the huff and puff method to investigate into the gas production potential from marine and permafrost hydrate deposits. ${ }^{21,22} \mathrm{~A}$ typical huff and puff cycle usually consists of three stages: injection, soaking, and production. During the injection stage, the hot water or steam is injected into the deposit from the well for a certain amount of time. Then the well is closed for some time in the soaking stage to allow heat diffusion. After that, the gas and water are pumped out of the deposit from the same well for a period of time. During the production stage, the well pressure will decrease continuously. When the pressure drops to a certain value, the next huff and puff cycle begins. It has been proved effective in gas production under suitable injection and production conditions.

To investigate the characteristics of hydrate decomposition in porous media of actual reservoir, one of the effective ways is to develop $3 \mathrm{D}$ experimental apparatus to simulate the hydrate dissociation process. So far, there are few reports on this aspect. Pang et al. ${ }^{10}$ investigated the dissociation kinetic behavior of methane hydrate using thermal method in a closed middlesized reactor of $10 \mathrm{~L}$ and observed a dramatically reduced dissociation rate phenomenon - "buffered dissociation" due to the ice melting. Yang et al. ${ }^{23}$ developed a cylindrical reactor with an inner diameter of $300 \mathrm{~mm}$ and an effective height of $100 \mathrm{~mm}$ and investigated the gas production performance from

Received: July 27, 2012

Revised: October 26, 2012

Published: November 1, 2012 




Figure 1. Schematic of the experimental apparatus.

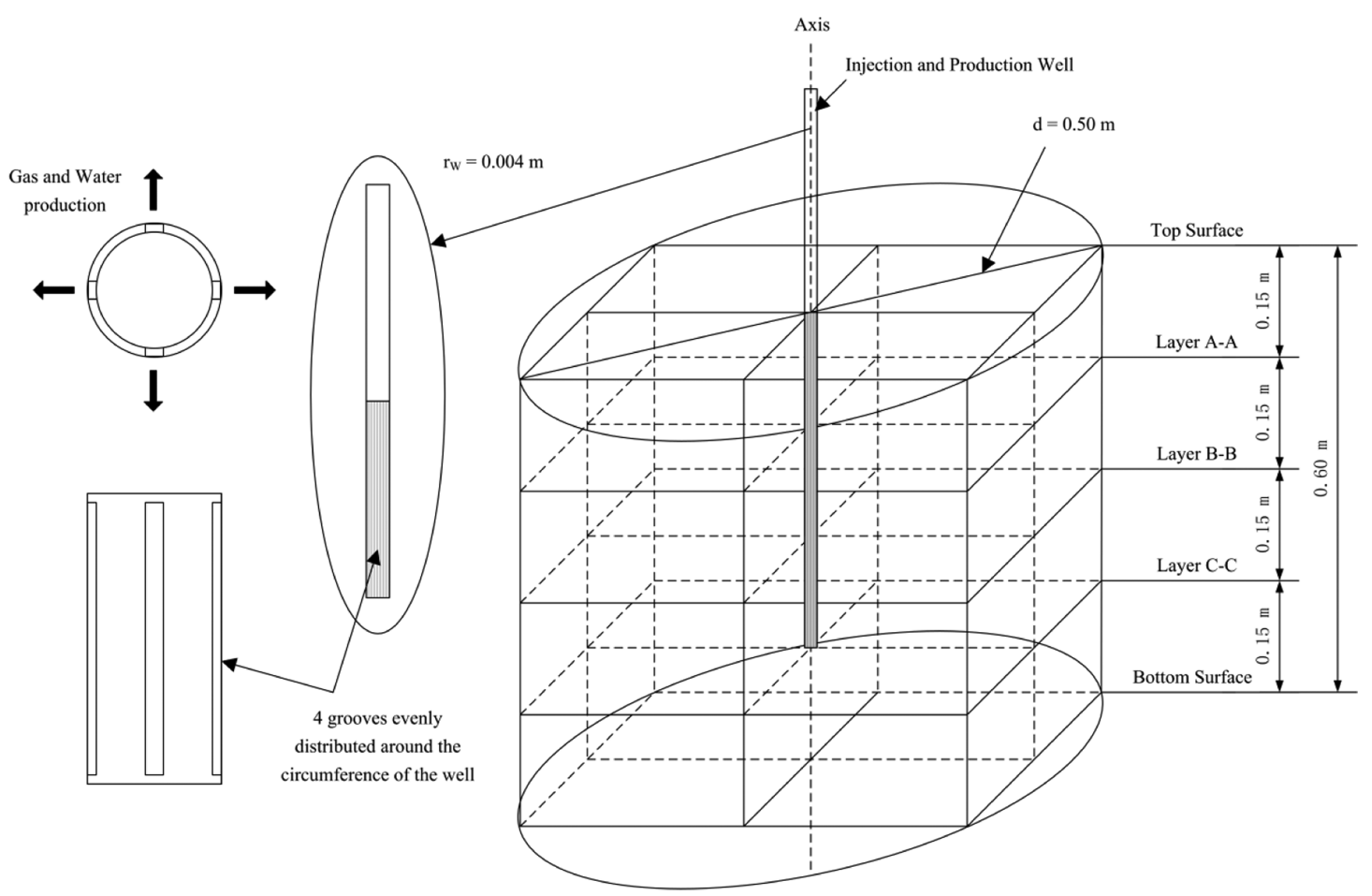

Figure 2. Schematic of the layers and the well design of the PHS.

methane hydrate. Recently, we have reported the investigation into the gas production behavior in a $3 \mathrm{D}$ cubic hydrate simulator (CHS) with the effective volume of $5.8 \mathrm{~L}$. Both the depressurization $^{24}$ and huff and puff ${ }^{25,26}$ methods have been employed to study the dissociation kinetic characteristics of methane hydrate in porous sediments. In addition, a pilot-scale hydrate simulator (PHS) with the effective volume of $117.8 \mathrm{~L}$ has been developed for hydrate formation and dissociation experiments, and some experimental results have been obtained using the huff and puff method. ${ }^{18}$

As another effective way of predicting the dynamic properties of hydrate dissociation in porous media, numerical simulation has been developing quickly in recent years. There have been various numerical codes developed for modeling nonisothermal hydration reactions in multiphase multicomponent systems. The TOUGH+HYDRATE $(\mathrm{T}+\mathrm{H})$ simulator is developed from TOUGH2 family codes at the Lawrence Berkeley National Laboratory. As one of the typical and representative codes, the $\mathrm{T}+\mathrm{H}$ has been widely used to simulate the hydrate formation and decomposition under conditions typical of common natural $\mathrm{CH}_{4}$-hydrate deposits (i.e., in the permafrost and in deep ocean sediments) in complex geological media at any scale (from laboratory to reservoir). ${ }^{27} \mathrm{Li}$ et al. used this code to evaluate the gas production potential from marine hydrate deposits in the Shenhu Area of South China $\mathrm{Sea}^{21}$ and permafrost hydrate deposits in Qilian Mountain ${ }^{22}$ with a single horizontal well by 


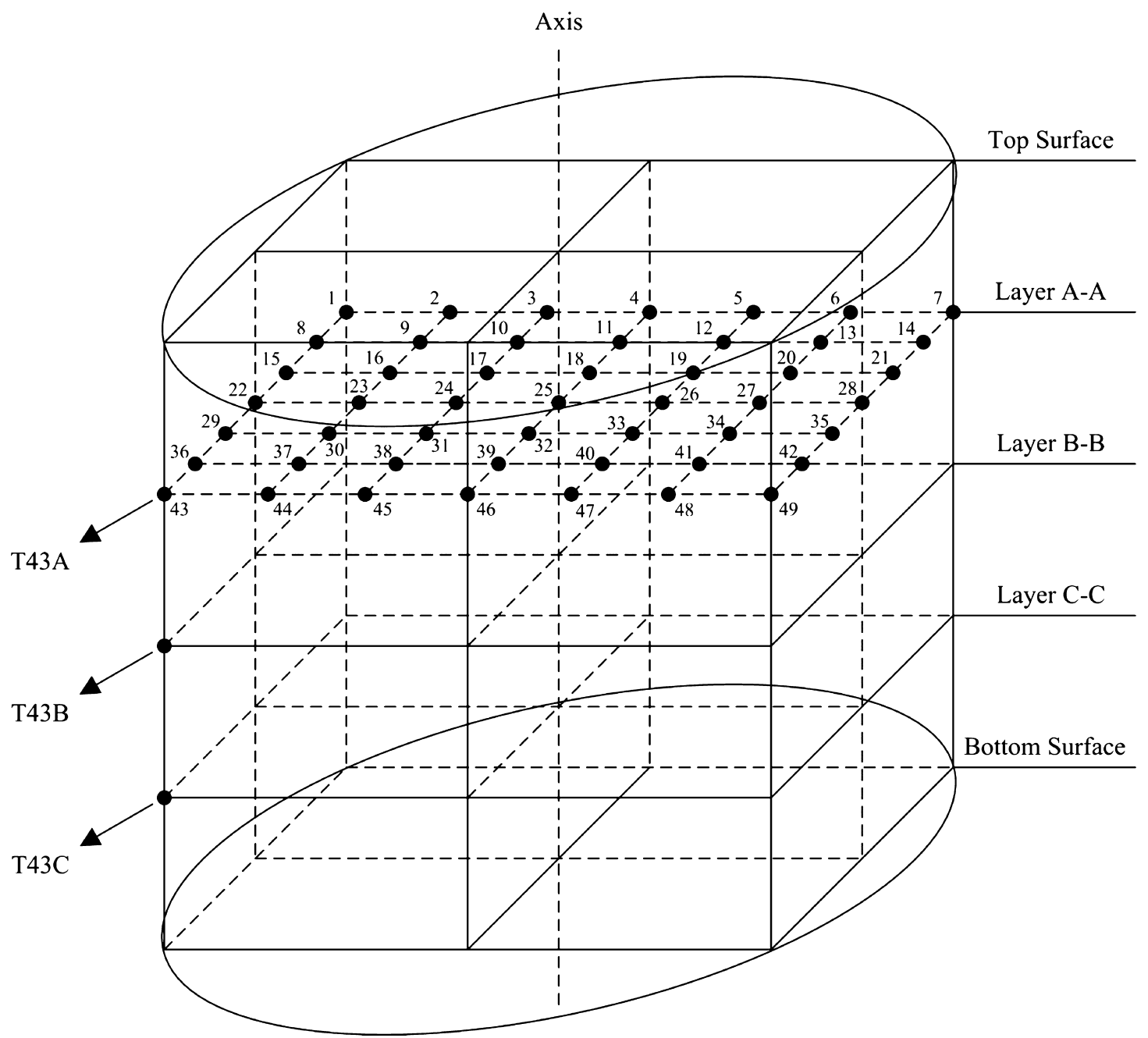

Figure 3. Schematic of the distribution of the thermometers in the PHS.

the huff and puff method. The results showed that the gas production was low from these hydrate deposits, but desirable gas-to-water ratio and energy efficiency could be obtained under suitable injection and production conditions in the Qilian Mountain permafrost hydrate deposits.

So far, the hydrate dissociation experiments in the PHS using the huff and puff method have been successfully carried out, but the corresponding numerical simulation has not yet been completed. In this work, we carried out both the experimental and numerical simulations to investigate the gas production behavior of methane hydrate in porous media using the huff and puff method in the PHS. The $\mathrm{T}+\mathrm{H}$ simulator was chosen for numerical modeling. The mathematical and numerical models of the $\mathrm{T}+\mathrm{H}$ code were validated by comparing the numerical and experimental results. A vertical well at the axis of the PHS was used as the injection and production well during the huff and puff process.

\section{EXPERIMENT}

2.1. Apparatus and Well Design. Figure 1 shows the schematic of the experimental apparatus used in this study, and a detailed description of the system is referred to in the published literature. ${ }^{18,28}$ The PHS is a cylindrical stainless steel that can withstand pressures of up to $30 \mathrm{MPa}$. The effective volume of the PHS is $117.8 \mathrm{~L}(0.60 \mathrm{~m}$ length and $0.50 \mathrm{~m}$ diameter). The PHS is surrounded by a water jacket $\left(-15-30^{\circ} \mathrm{C}, \pm 0.1^{\circ} \mathrm{C}\right)$, and the whole apparatus is placed in a walk-in cold room $\left(-8-30{ }^{\circ} \mathrm{C}, \pm 2{ }^{\circ} \mathrm{C}\right)$, which can provide the lowtemperature conditions necessary for hydrate formation. Figure 2 shows the schematic of the layers and the well design of the PHS. As shown in Figures 1 and 2, the PHS is divided equally into four regions by three horizontal layers inside the vessel: the Layers $\mathrm{A}-\mathrm{A}, \mathrm{B}-\mathrm{B}$, and $\mathrm{C}-\mathrm{C}$. Each region has a height of $0.15 \mathrm{~m}$. The central vertical well, with the radius of $r_{\mathrm{W}}=0.004 \mathrm{~m}$, is fixed at the axis of the PHS and extends into the vessel to the Layer $\mathrm{C}-\mathrm{C}$. It is used as the injection and production well during the huff and puff experiment.

As shown in Figure 2, there are four grooves evenly distributed along the circumference of the vertical well, and the grooves extend from the Top Surface of the PHS to the Layer C-C. Both the injected hot water and the produced fluid flow from these grooves. Previous studies have proposed two kinds of well design in gas production: (1) a single well with hot water injection and gas production simultaneously ${ }^{29,30}$ and (2) a single well with hot water circulating inside the wellbore without coming in contact with the hydrate deposits. ${ }^{31}$ Comparing with them, this kind of well design is much simpler and technologically feasible. Previous numerical studies have demonstrated the effectiveness of a similar grooved well design in gas production from marine and permafrost hydrate deposits. ${ }^{21,22}$ Figure 3 shows the schematic of the distribution of the thermometers (the temperature measuring spots) in the PHS. There are a total of 147 thermometers evenly distributed in the PHS, with 49 spots on each layer (Layers $\mathrm{A}-\mathrm{A}, \mathrm{B}-\mathrm{B}$, and $\mathrm{C}-\mathrm{C}$ ). T25 is located at the center, and $\mathrm{T} 1, \mathrm{~T} 7, \mathrm{~T} 43$, and T49 are placed at the corner close to the cylindrical boundary. With the temperature records of these thermometers, we 
can obtain the profiles of the evolution of the spatial distribution of $T$ during the experiment.

The system pressure is measured with two pressure transducers. The "Inlet Pressure" transducer is located at the bottom of the PHS to measure the pressure of the base of the hydrate deposit, and the "Outlet Pressure" transducer is situated in the production well (the outlet of the well). A back-pressure regulator is connected to the outlet of the PHS to control the pressure of the production well. The cumulative gas injected into the PHS, the gas production rate, and the cumulative gas produced from the vessel are measured with two gas flow meters, which are situated in the inlet and outlet of the PHS, respectively. A balance is used to measure the mass of the produced liquid from the PHS. The performance and operation parameters of these transducers and devices as well as other related apparatus shown in Figure 1 are described in detail in the published literature. ${ }^{18,28}$

2.2. Experimental Procedure. The raw dry quartz sand with a size range between 300 and $450 \mu \mathrm{m}$ was tightly packed in the PHS. The whole experiment consists of two stages: the hydrate formation stage and the dissociation stage. Figure 4 shows the evolutions of the

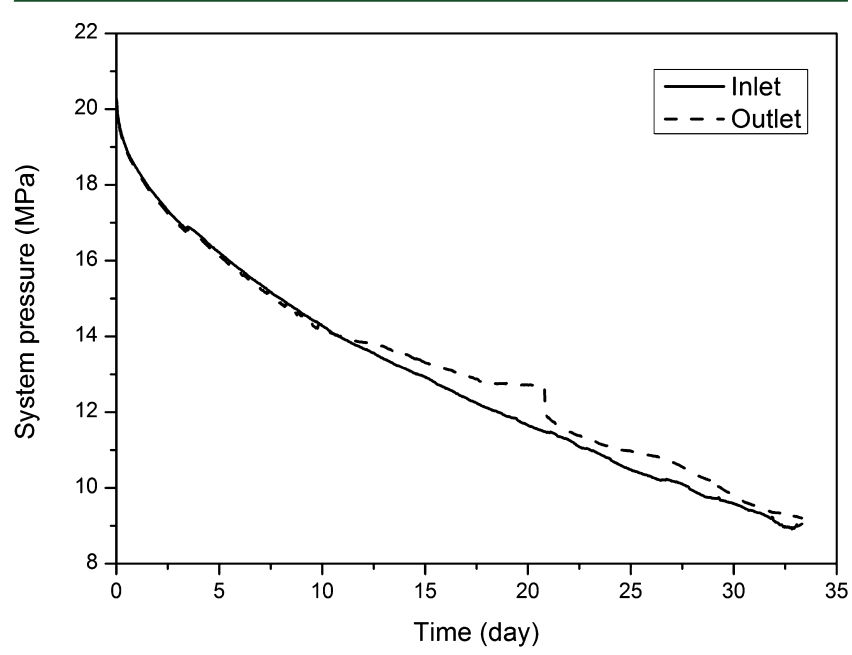

Figure 4. Evolutions of the Inlet and Outlet pressure during the hydrate formation.

Inlet and Outlet pressure during the hydrate formation stage. At the beginning of the hydrate formation process, the vessel was pressurized to approximately $20 \mathrm{MPa}$ with methane gas and deionized water injection. The initial pore volume saturations of gas and water are 0.341 and 0.659 , respectively. The total volume of gas before formation is $17.51 \mathrm{~L}(4,369 \mathrm{~L}$ in standard state). Then the vessel was closed as an isochoric system. After that, the temperature of the water jacket was gradually reduced to $7.3{ }^{\circ} \mathrm{C}$ as the hydrate formation equilibrium temperature. Using the fugacity model of $\mathrm{Li}$ et al., ${ }^{32}$ the equilibrium hydrate dissociation pressure at the working temperature was calculated to be about 5.3 $\mathrm{MPa}$, which was much lower than the initial system pressure. The hydrate formation stage lasted for about 33 days, and the pressure of the vessel gradually decreased to 9.0 MPa. As shown in Figure 4, the descent speed of the Inlet and Outlet pressure declined due to the decreased driving force after this formation stage, so the hydrate formation experiment was halted at $t=33$ days. The difference between the Inlet and the Outlet pressure during the late formation stage indicates that the solid hydrate may obstruct the gas diffusion in the PHS

Then the following procedure was carried out to investigate into the dissociation behavior of methane hydrate using the huff and puff method. First, the pressure of the production well was gradually decreased to $5.53 \mathrm{MPa}$, which is slightly higher than the equilibrium pressure of 5.3 MPa. Gas was released from the vessel under the pressure driving force. Second, the vessel was closed for about $30 \mathrm{~min}$, and the system pressure and temperature maintained stable, which indicated little hydrate dissociation during this period. After that, the experimental and numerical simulation began $(t=0)$, and the huff and puff process was carried out for hydrate dissociation. The initial pressure and temperature of the vessel before hot water injection were $5.53 \mathrm{MPa}$ and $7.18{ }^{\circ} \mathrm{C}$, respectively. Each huff and puff cycle consisted of the following three stages: injection, soaking, and production. During the injection stage, hot water was injected into the vessel through the central vertical well to heat the deposit. The initial temperature of the injected hot water $T_{\text {inj }}$ at the inlet of the well was about $85{ }^{\circ} \mathrm{C}$, and it maintained stable. The injection rate $Q_{\text {inj }}$ and the duration of the hot water injection $t_{\text {inj }}$ maintained $0.2 \mathrm{~L} / \mathrm{min}$ and 20 $\mathrm{min}$, respectively. In the soaking stage, the injection well was closed for 30 min to allow the heat diffusion in the deposit. Then, during the production stage, the released gas and water were produced through the well by setting the back-pressure regulator pressure to $4.7 \mathrm{MPa}$. Once the system pressure declined to $4.7 \mathrm{MPa}$, the next huff and puff cycle began. This process was repeated until the system pressure stopped rising in the soaking stage. A total of 15 huff and puff cycles were carried out during the experiment. During the hydrate dissociation, the temperatures and pressures in the vessel, the water production rate, the gas production rate, and the cumulative gas produced were recorded by the data acquisition system at $20 \mathrm{~s}$ intervals.

\section{NUMERICAL SIMULATION}

3.1. The Numerical Simulation Code. In the numerical simulation study, we used both the serial and parallel versions of the TOUGH+HYDRATE code. ${ }^{27,33}$ This code can model nonisothermal hydration reactions, phase behavior, and flow of fluids and heat under the conditions typical of natural $\mathrm{CH}_{4}$ hydrate deposits in complex geologic media. The model accounts for heat and four mass components (i.e., water, $\mathrm{CH}_{4}$, hydrate, and water-soluble inhibitors such as salts or alcohols) that are partitioned among four possible phases: gas, aqueous liquid, ice, and hydrate. A total of 15 states (phase combinations) can be described by the code, which can handle any combination of hydrate dissociation mechanisms. In this code, the impact of the movement and the volume expansion of the sediments are neglected.

3.2. System Properties and Domain Discretization. The system properties and parameters used in this simulation are shown in Table 1 . The intrinsic permeability $k$ (3.0 Darcies) and the wettability properties as well as other related parameters of the system are estimated based on the properties of quartz sand, of which the size range is $300-450 \mu \mathrm{m}$.

Figure 5 shows the simulation grid of the PHS. Because of axial symmetry, the cylindrical PHS is discretized into a radially symmetric mesh. It consists of $47 \times 102=4,794$ elements in $(r$, $z$ ), of which 4,601 are active (the remaining being boundary cells). The discretization along the $r$-axis is nonuniform, and it is discretized into 46 gridblocks within the PHS $(0<r \leq 0.25$ $\mathrm{m})$. The thickness of the gridblocks $\Delta r$ increases from 0.002 to $0.007 \mathrm{~m}$. The PHS is discretized into 100 gridblocks uniformly along the $z$-axis $(-0.3 \mathrm{~m}<z<0.3 \mathrm{~m})$ with the thickness of $\Delta z$ $=0.006 \mathrm{~m}$. The uppermost $(z>0.30 \mathrm{~m})$ and lowermost $(z<$ $-0.30 \mathrm{~m}$ ) layers are the top and bottom boundaries with the thickness of $\Delta z=0.007 \mathrm{~m}$. The gridblocks of $r>0.25 \mathrm{~m}$ correspond to the cylindrical boundaries of the PHS, and their thickness is $\Delta r=0.007 \mathrm{~m}$. All the boundary elements are impermeable and inactive during the simulation process, which means no fluids flow and constant pressure and temperature conditions. Assuming an equilibrium reaction of hydrate dissociation without inhibitors, this grid results in 14,382 coupled equations to be solved simultaneously.

Based on the well design of the experiment, a string of gridblocks with the radius of $r_{\mathrm{W}}=0.004 \mathrm{~m}$ from the top surface 
Table 1. Hydrate Deposit Properties and Conditions in the PHS

\begin{tabular}{|c|c|}
\hline parameter & value \\
\hline height of the PHS $h$ & $0.60 \mathrm{~m}$ \\
\hline diameter of the PHS $d$ & $0.50 \mathrm{~m}$ \\
\hline volume of the PHS $V$ & $117.8 \mathrm{~L}$ \\
\hline initial pressure $P_{0}$ & $5.53 \mathrm{MPa}$ \\
\hline initial temperature $T_{0}$ & $280.63 \mathrm{~K}\left(7.48{ }^{\circ} \mathrm{C}\right)$ \\
\hline density of the quartz sand & $2600 \mathrm{~kg} / \mathrm{m}^{3}$ \\
\hline gas composition & $100 \% \mathrm{CH}_{4}$ \\
\hline initial saturations in the PHS & $S_{\mathrm{H}}=0.292, S_{\mathrm{G}}=0.326, S_{\mathrm{A}}=0.382$ \\
\hline intrinsic permeability $k_{\mathrm{r}}=k_{z}$ & $3.0 \times 10^{-12} \mathrm{~m}^{2}(=3.0 \mathrm{D})$ \\
\hline porosity $\phi$ & 0.435 \\
\hline water salinity & 0 \\
\hline wet thermal conductivity $k_{\Theta \mathrm{RW}}$ & $3.1 \mathrm{~W} /(\mathrm{m} \cdot \mathrm{K})$ \\
\hline dry thermal conductivity $k_{\Theta \mathrm{RD}}$ & $1.0 \mathrm{~W} /(\mathrm{m} \cdot \mathrm{K})$ \\
\hline $\begin{array}{l}\text { composite thermal conductivity } \\
\text { model }^{27,37}\end{array}$ & $\begin{array}{c}k_{\Theta \mathrm{C}}=k_{\Theta \mathrm{RD}}+\left(S_{\mathrm{A}}^{1 / 2}+S_{\mathrm{H}}^{1 / 2}\right)\left(k_{\Theta \mathrm{RW}}-\right. \\
\left.k_{\Theta \mathrm{RD}}\right)+\varphi S_{\mathrm{I}} k_{\Theta \mathrm{I}}\end{array}$ \\
\hline capillary pressure model ${ }^{38}$ & $\begin{array}{l}P_{\text {cap }}=-P_{01}\left[\left(S^{*}\right)^{-1 / \lambda}-1\right]^{1-\lambda} \\
S^{*}=\left(S_{\mathrm{A}}-S_{\mathrm{irA}}\right) /\left(S_{\mathrm{mXA}}-S_{\mathrm{irA}}\right)\end{array}$ \\
\hline$S_{\text {irA }}$ & 0.04 \\
\hline$\lambda$ & 0.45 \\
\hline$P_{01}$ & $10^{5} \mathrm{~Pa}$ \\
\hline \multirow[t]{4}{*}{ relative permeability model ${ }^{27}$} & $k_{\mathrm{rA}}=\left(S_{\mathrm{A}}^{*}\right)^{n}$ \\
\hline & $k_{\mathrm{rG}}=\left(S_{\mathrm{G}} *\right)^{n G}$ \\
\hline & $S_{\mathrm{A}}^{*}=\left(S_{\mathrm{A}}-S_{\mathrm{irA}}\right) /\left(1-S_{\mathrm{irA}}\right)$ \\
\hline & $S_{\mathrm{G}} *=\left(S_{\mathrm{G}}-S_{\mathrm{irG}}\right) /\left(1-S_{\mathrm{irA}}\right)$ \\
\hline$n$ & 3.572 \\
\hline$n_{\mathrm{G}}$ & 3.572 \\
\hline$S_{\mathrm{irG}}$ & 0.23 \\
\hline$S_{\text {irA }}$ & 0.10 \\
\hline
\end{tabular}

to the Layer $\mathrm{C}-\mathrm{C}$ are set to be the injection and production wells at the axis of the PHS, as shown in Figure 5. To avoid a theoretically correct but computationally intensive solution of the Navier-Stokes equation, ${ }^{34}$ these wells are simulated as pseudoporous media with $\phi=1.0, k=3.0 \times 10^{-9} \mathrm{~m}^{2}(3000$ Darcies), and a capillary pressure $P_{\text {cap }}=0$.

3.3. Initial and Boundary Conditions. At the beginning of the huff and puff process $(t=0)$, the domain of the PHS is saturated with three phases: hydrate, gas, and water. Based on the experimental results, the initial $S_{\mathrm{H}}, S_{\mathrm{G}}$, and $S_{\mathrm{A}}$ before hot water injection are calculated to be $0.292,0.326$, and 0.382 , respectively, as shown in Table 1. According to the experimental results, the initial pressure $P_{0}$ is set to be 5.53 $\mathrm{MPa}$, and the initial temperature $T_{0}$ is computed by the $\mathrm{T}+\mathrm{H}$ internally to be $280.63 \mathrm{~K}\left(7.48{ }^{\circ} \mathrm{C}\right)$ with the equilibrium model of methane gas. It is in accordance with the experimental value of $280.33 \mathrm{~K}\left(7.18{ }^{\circ} \mathrm{C}\right.$, the average of the 147 thermometers), which indicates the accuracy of the $P-T$ equilibrium model of the $\mathrm{T}+\mathrm{H}$ code. Thus the initial values of the primary variables $\left(P, S_{A}\right.$ and $\left.T\right)$ of each grid have been determined.

Figure 6 shows the profile of the boundary temperature $T_{\mathrm{B}}$ of the experimental results during hydrate dissociation in the PHS. It shows the characteristics in each huff and puff cycle that the temperature of the stainless steel boundary rises continuously during the hot water injection stage and the soaking stage, while it drops down sharply in the production stage. This is caused by the heat conduction between the boundary and the deposit during the huff and puff process. The boundary temperature of the numerical simulation process is based on the experimental results shown in Figure 6.



Figure 5. Schematic of the grid used in the numerical simulation.

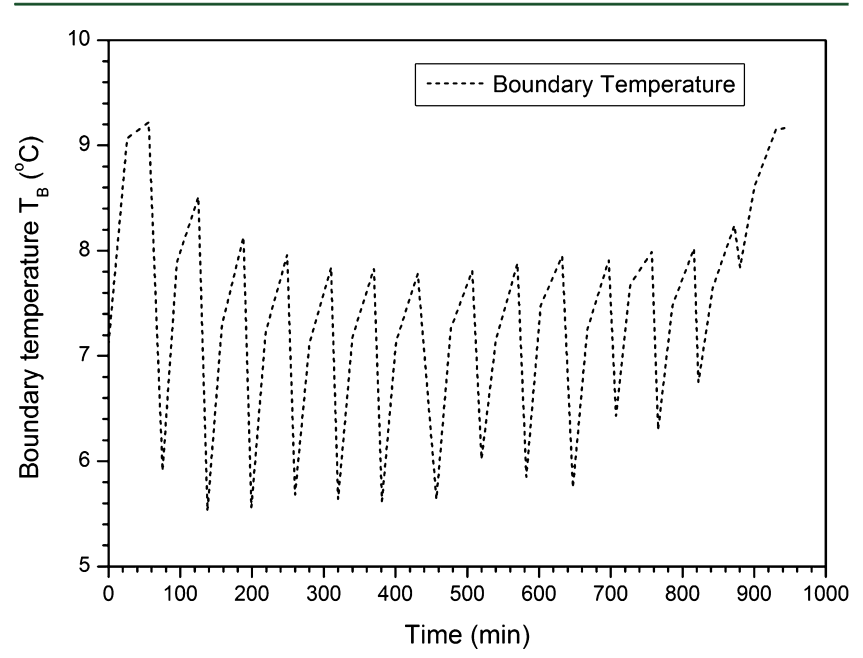

Figure 6. Boundary temperature $T_{\mathrm{B}}$ profile of the experimental results during hydrate dissociation in the PHS.

3.4. Simulation Procedure. Based on the experimental results, the numerical simulation course consists of 15 huff and puff cycles. Each cycle is divided into three stages (injection, soaking, and production) to simulate separately. For example, at the beginning of the injection stage of the first cycle $(t=0)$, 
the hot water is injected into the PHS with constant rate of $Q_{\text {inj }}$ $=0.2 \mathrm{~L} / \mathrm{min}$ for $20 \mathrm{~min}$ through the injection well, as shown in Figure 5. When the injection stage is over, the soaking starts immediately, and the mass injection and production rates of the well are set to be 0 . After $30 \mathrm{~min}$ of soaking, the production stage starts and lasts for about $19.33 \mathrm{~min}$, which is the duration of the production stage of the first cycle in the experiment simulation. During this stage, the well performs as a sink term, and the constant mass production rate $Q_{\text {pro }}$ is determined through a trial-and-error simulation process that results in the known system pressure of $P=4.7 \mathrm{MPa}$ at the end of the production stage. When the first cycle ends, the second cycle begins with similar operation conditions and so on. According to the experiment, the temperature and the salinity of the injected hot water maintain $T_{\mathrm{inj}}=85{ }^{\circ} \mathrm{C}$ and $X_{\mathrm{S}}=0$, respectively.

\section{RESULTS AND DISCUSSION}

4.1. Pressure Profiles and Spatial Distribution. Figure 7 shows the comparison of the experimental and numerical

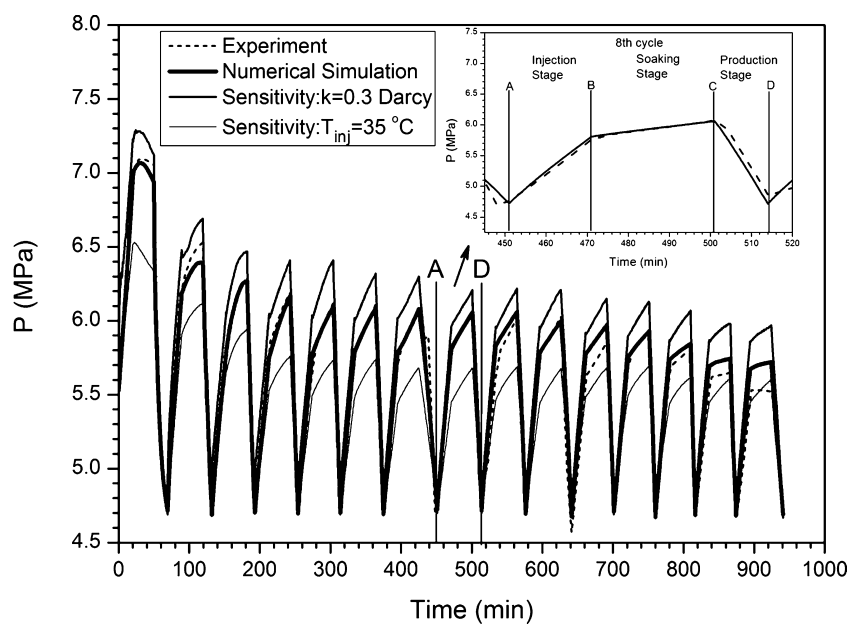

Figure 7. Comparison of the experimental and numerical simulation results of the system pressure $P$ during hydrate dissociation in the PHS and its sensitivities to $k$ and $T_{\text {inj }}$ of the numerical simulation.

simulation results of the system pressure $P$ over time during hydrate dissociation in the PHS. Both the experimental and numerical simulation results show a regular fluctuation of the system pressure during the huff and puff process. As a typical example, the pressure evolution with time of the eighth cycle is shown in the partial enlarged plot of Figure 7. It starts at $t=$ $451 \mathrm{~min}$ (Point A) and ends at $t=514 \mathrm{~min}$ (Point D). In the hot water injection stage of 451-471 $\mathrm{min}(\mathrm{A}-\mathrm{B})$, the system pressure increases continuously to approximately $5.80 \mathrm{MPa}$, which is caused by (i) the mass injection, (ii) the released gas from hydrate dissociation under thermal stimulation, and (iii) the thermal expansion effect of methane gas under high temperature conditions. Within the soaking stage of 471-501 $\min (B-C)$, the system pressure continues increasing when the injected heat diffuses from the well to the deposit to promote more hydrate dissociation. However, the increment speed in the soaking stage is much lower than that in the injection stage, which indicates a limited hydrate dissociation rate caused by the decreased heat conduction efficiency in this period. During the production stage of 501-514 $\mathrm{min}$ (C-D), the PHS is depressurized sharply from about 6.07 to $4.70 \mathrm{MPa}$, and both gas and water are produced from the vessel through the production well. The fluctuation range of the pressure nearly keeps the same in each cycle except the first one, which is because the first cycle starts at $P=5.53 \mathrm{MPa}$, while the others begin at $P=4.70 \mathrm{MPa}$. It also shows that the maximum pressure of each cycle gradually declines due to the decreased hydrate dissociation rate.

Figure 8 shows the numerical simulation results of the evolution of the $P$ spatial distribution during hydrate
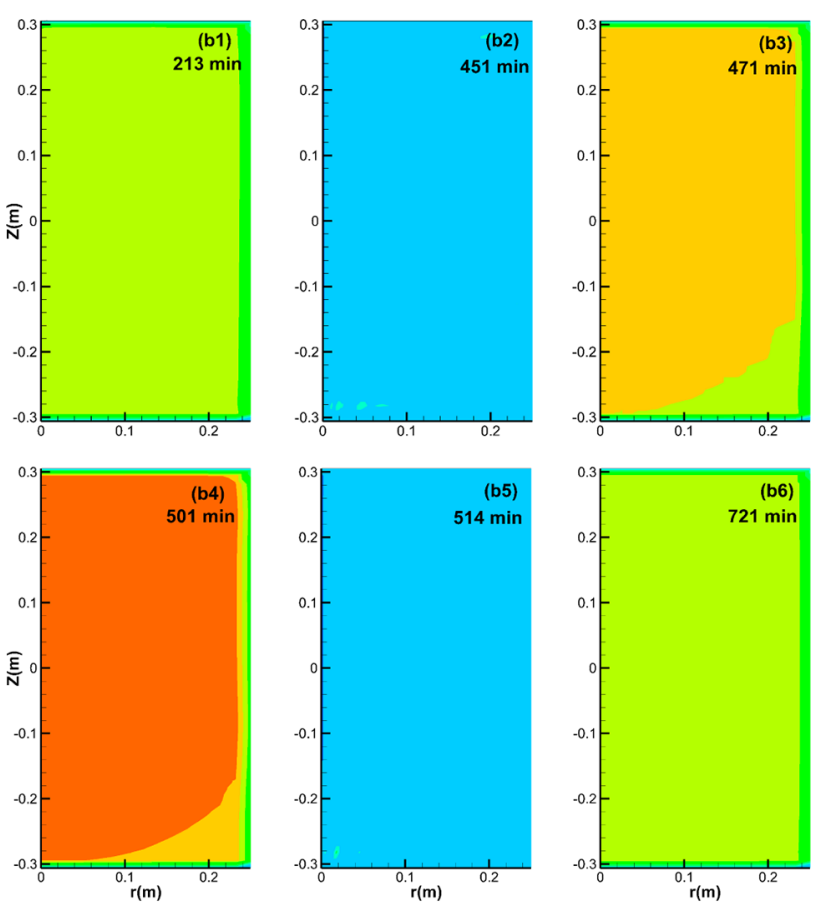

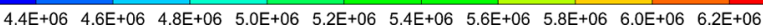

Figure 8. Evolution of the spatial distribution of $P$ during hydrate dissociation in the PHS.

dissociation in the PHS. In this study, the figures marked with "a" represent the experimental results, while those with "b" represent the corresponding numerical simulation results. The time points of figures $\mathrm{b} 1$ and $\mathrm{b} 6$ are the end of the injection stage of the fourth and the 12th huff and puff cycles, respectively, and figures $\mathrm{b} 2-\mathrm{b} 5$ correspond to the four time points of $A-D$ in the eighth cycle shown in the enlarged plot of Figure 7, respectively. We can see that the pressures at different locations in the PHS have little discrepancy because of the high porosity and permeability of the sediment, which validates the experimental assumption that the pressure at any point of the PHS can be taken as the system pressure, including the pressures measured by the Inlet and Outlet Pressure transducers used in the experiment. The pressure at each time point in Figure 8 is in accordance with that shown in Figure 7. Figure 8 (b1, b3, and b6) shows that the system pressure increases approximately to the same level at the end of each injection stage, which means the pressure fluctuation in this stage is mainly controlled by the amount of the injected hot water. Comparing Figure 8(b2) with Figure 8(b5), we can see that the pressure decreases exactly to $4.70 \mathrm{MPa}$ at the end of each production stage. During a single huff and puff cycle, the pressure increases to the maximum at the end of the soaking stage, as shown in Figure 8(b4). 
4.2. Gas and Water Production. Figures 9 and 10 show the comparisons of the experimental and numerical simulation

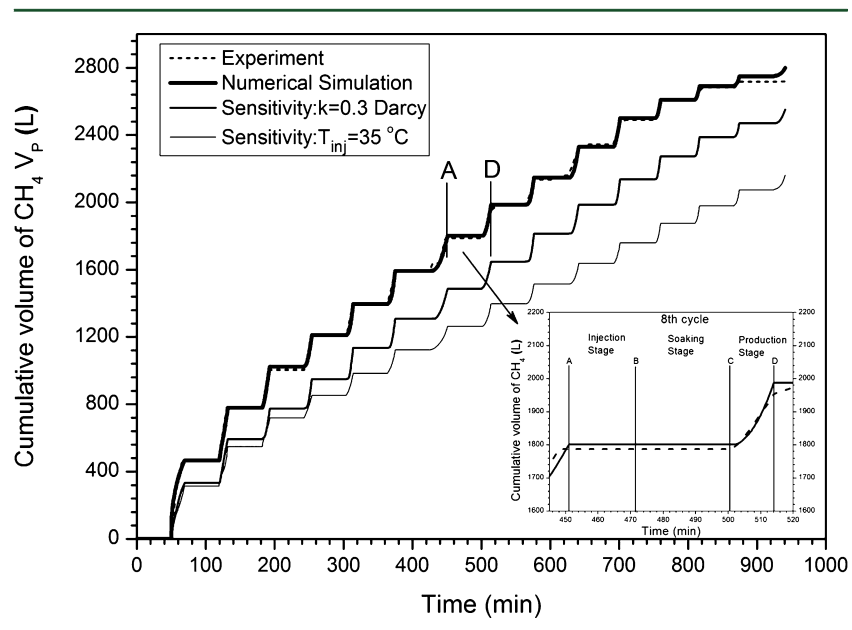

Figure 9. Comparison of the experimental and numerical simulation results of the cumulative gas produced $V_{\mathrm{P}}$ during hydrate dissociation in the PHS and its sensitivities to $k$ and $T_{\mathrm{inj}}$ of the numerical simulation.



Figure 10. Comparison of the experimental and numerical simulation results of the cumulative water produced $V_{\mathrm{W}}$ during hydrate dissociation in the PHS and its sensitivities to $k$ and $T_{\text {inj }}$ of the numerical simulation.

results of the cumulative volume of the produced gas $\left(V_{\mathrm{P}}\right)$ and water $\left(V_{\mathrm{W}}\right)$ during the hydrate dissociation in the PHS. Both of them increase with time in the form of ladder. As a typical example, the gas and water production of the eighth cycle (AD) are also shown in the partial enlarged plots of Figures 9 and 10 , respectively. Hot water is injected into the vessel in the injection stage $(A-B)$ with constant rate $Q_{\text {inj }}=0.2 \mathrm{~L} / \mathrm{min}$ for $20 \mathrm{~min}$, and the amount of the injected mass is $4.0 \mathrm{~kg}$. When the well is closed, there is no fluid injection or production in the soaking stage $(\mathrm{B}-\mathrm{C})$. Both of the $V_{\mathrm{P}}$ and $V_{\mathrm{W}}$ maintain constant in 451-501 $\mathrm{min}(\mathrm{A}-\mathrm{C})$. When the production stage starts, gas and water are produced from the vessel continuously. The cumulative volume of the produced gas and water of the numerical simulation during this production stage $(\mathrm{C}-\mathrm{D})$ are about 186 and $3.38 \mathrm{~L}$, respectively, while they are 167 and 3.40 $\mathrm{L}$, respectively, in the experiment. The numerical results agree well with the experiment, which indicates the accuracy of the fluids flow model used in this study.
As shown in Figure 9, the volume of the produced $\mathrm{CH}_{4}$ in the first cycle is relatively higher than the others. This is because the PHS is depressurized from about 7.06 to $4.70 \mathrm{MPa}$ in the first production stage, while others are from less than 6.50 $\mathrm{MPa}$ (Figure 7). In addition, the gas production rate maintains approximately stable in a relatively long period (second-11th cycles), which indicates a steady heat absorption and hydrate dissociation process. In the later production stage (12th-15th cycles), the cumulative gas produced in each cycle gradually decreases over time because the hydrate dissociation rate decreases when the heat conduction efficiency reduces with the expansion of the dissociation area. The average gas production rate $Q_{\text {avg }}$ is about $2.89 \mathrm{~L} / \mathrm{min}$ in the end. During the entire huff and puff process $(0-941 \mathrm{~min})$, the water is produced from the vessel with an average rate of about $3.8 \mathrm{~L} /$ cycle, and the difference of the water production between each cycle is very slight. However, this average water production rate is lower than the hot water injection rate $(4.0 \mathrm{~L} /$ cycle $)$ in each cycle, which indicates that some of the injected water is retained in the vessel. So the water production is manageable when using the huff and puff method for hydrate dissociation. Similar results of the gas and water production behaviors using the huff and puff method have been concluded in previous studies. ${ }^{18,22,26}$

Figure 11 shows the comparison of the experimental and numerical simulation results of the gas-to-water ratio $R_{\mathrm{GW}}=$

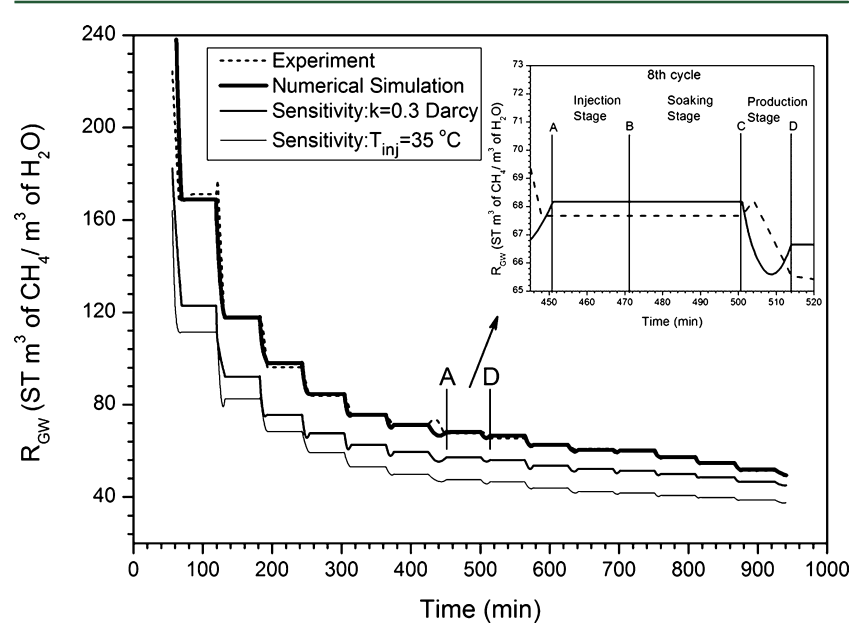

Figure 11. Comparison of the experimental and numerical simulation results of the gas-to-water ratio $R_{\mathrm{GW}}$ during hydrate dissociation in the PHS and its sensitivities to $k$ and $T_{\text {inj }}$ of the numerical simulation.

$V_{\mathrm{P}} / V_{\mathrm{W}}$ during hydrate dissociation in the PHS. $\mathrm{R}_{\mathrm{GW}}$ is a relative criterion of gas production performance and can measure the effectiveness of hydrate dissociation as a gas-producing method. It is shown that $R_{\mathrm{GW}}$ declines quickly to approximately 75.5 ST $\mathrm{m}^{3}$ of $\mathrm{CH}_{4} / \mathrm{m}^{3}$ of $\mathrm{H}_{2} \mathrm{O}$ after the first 5 huff and puff cycles $(0-$ $314 \mathrm{~min}$ ). After that, the descent speed slows down because of the relatively stable gas and water production rate in this period (Figures 9 and 10). At the end of the experiment, $R_{\mathrm{GW}}$ declines to the minimum of about 49.5. As shown in the partial enlarged plot of Figure 11, the $R_{\mathrm{GW}}$ maintains stable during the injection and soaking stages, and it rises slightly in the early production stage in the experiment. It may be because some of the released methane gas gradually accumulates at the top of the vessel because of buoyancy during the soaking stage, and it further results in a higher gas production rate and a lower water 
production rate in the early production stage (as shown in Figures 9 and 10).

Figure 12 shows the comparison of the experimental and numerical simulation results of the energy efficiency $\eta$ during



Figure 12. Comparison of the experimental and numerical simulation results of the energy efficiency $\eta$ during hydrate dissociation in the PHS and its sensitivities to $k$ and $T_{\text {inj }}$ of the numerical simulation.

hydrate dissociation in the PHS. It is defined as the ratio of the amount of energy produced in the form of $\mathrm{CH}_{4}$ to the energy provided to the reservoir, ${ }^{22}$ as shown in the following equation

$$
\eta=\Delta H_{\mathrm{c}} /(W+Q)
$$

where $\Delta H_{\mathrm{c}}$ is the total enthalpy of combustion of $\mathrm{CH}_{4}$ ( $1 \mathrm{~atm}$, $\left.25^{\circ} \mathrm{C}, 889.6 \mathrm{~kJ} / \mathrm{mol}\right), W$ is the pressurization energy consumed by the pump, ${ }^{22}$ and $Q$ is the heat used for heating the injected water. It is assumed that the water is heated from $20{ }^{\circ} \mathrm{C}$ to the injection temperature $T_{\text {inj. }}$ It is shown in the partial enlarged plot of Figure 12 that $\eta$ increases in the production stage (CD), while it drops down in the injection stage when the heat and the pressurization energy is consumed by the system. During the whole huff and puff process, $\eta$ gradually decreases from the maximum of about 16.5 to the minimum of about 6.5 in the Reference Case.

4.3. Spatial Distribution of $T$. Figure 13 shows the comparison of the evolutions of the $T$ spatial distributions over time of the experimental and numerical simulation results during hydrate dissociation using the huff and puff method in the PHS. Figures 13(a1)-(a6) are the experimental temperature results that are obtained by the 147 thermometers distributed in the three layers shown in Figure 3. The numerical results of the $T$ distribution over time are shown in Figures 13(b1)-(b6), and because of axial symmetry, only a crosssection of the PHS is plotted. The temperature measuring spots in Figures 13(a1), (b1), and (b2) are in accordance with the distributions of the thermometers shown in Figure 3. The time points of Figures 13(a1)-(a6) and (b1)-(b6) are the same as those mentioned in Figure 8 . The solid rectangle formed by T25A, T25C, T28C, and T28A in Figure 13(b1) corresponds to that in Figure 13(a1). The dashed rectangle of T25A, T25C, T7C, and T7A in Figure 13(b2) corresponds to that in Figure 13(a1).

Generally, the numerical results of the $T$ distribution at each time point show fine agreements with the experiment, which indicates the accuracy of the heat transfer model used in this
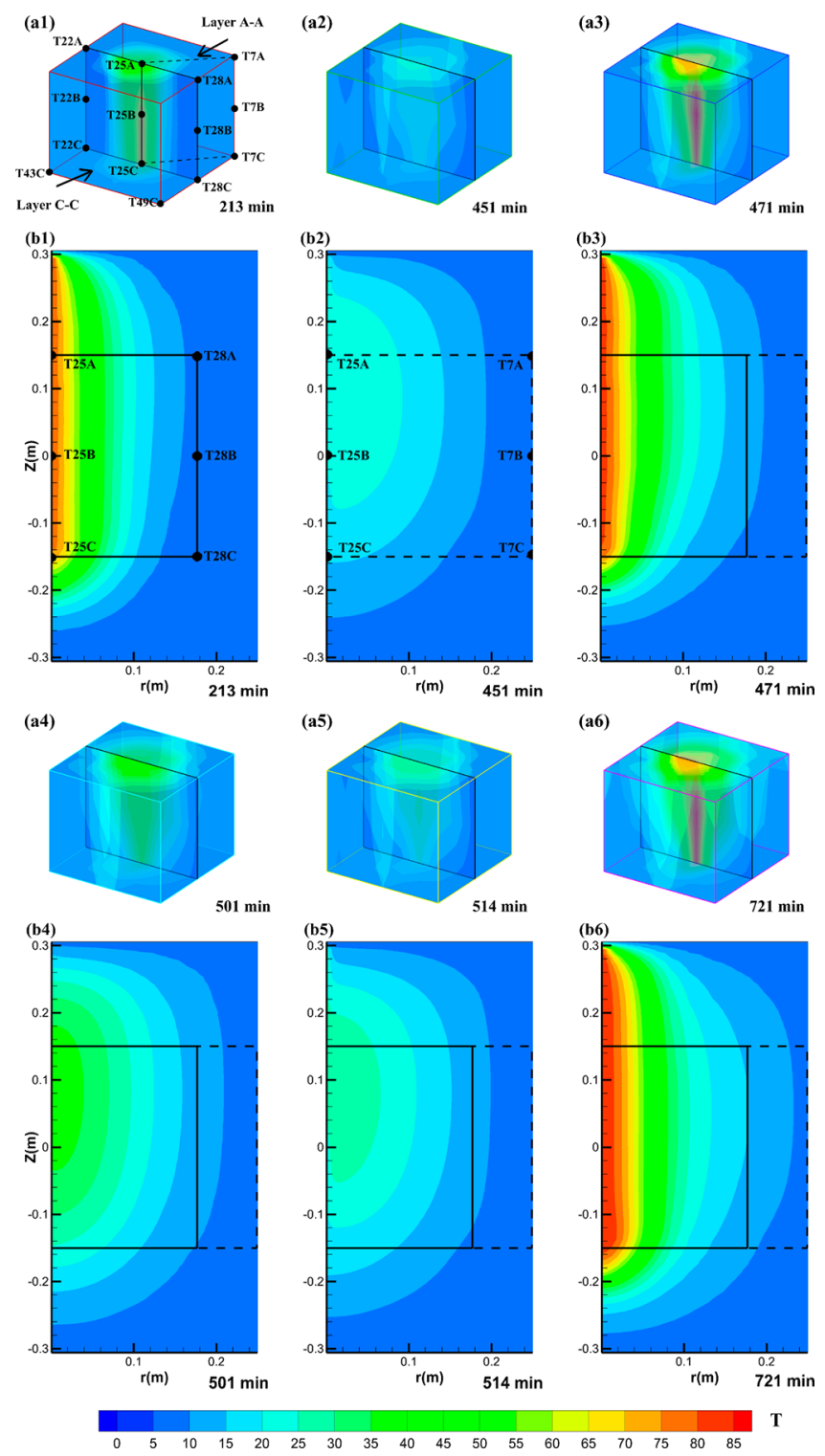

Figure 13. Comparison of spatial distributions of $T$ over time of experimental $(\mathrm{a} 1-\mathrm{a} 6)$ and numerical simulation (b1-b6) results during hydrate dissociation in the PHS.

study. Both of the experimental and numerical results show the following characteristics during the injection stage: (i) the highest temperature $\left(T>80^{\circ} \mathrm{C}\right)$ in the PHS is observed in the vicinity of the injection well, and the high- $T$ region gradually enlarges in different injection stages, indicating more heat absorbed by the quartz sand and the external surroundings during the huff and puff process; (ii) the injected hot water has an approximately cylindrical moving front around the well. With the constant injection rate $Q_{\text {inj }}=0.2 \mathrm{~L} / \mathrm{min}\left(t_{\text {inj }}=20 \mathrm{~min}\right)$ and assuming that the hot water flows from the well to the inner deposit of the PHS along the $r$-axis, the calculated radius of the hot water moving front at the end of the injection stage during each huff and puff cycle is approximately $r=0.08 \mathrm{~m}$, which is about in the region of $T>35^{\circ} \mathrm{C}$, as shown in Figures 13(b1), (b3), and (b6). It is much smaller than the thermal effect range (defined as the area of $T>10^{\circ} \mathrm{C}$ ) within which the hydrate is thought to be completely dissociated, so the conduction performs as the main heat transfer pattern in the PHS, which is coincident with the results of previous 
studies. $^{21,22}$ The thermal effect range gradually enlarges with the huff and puff process going on, as shown in Figures 13(a1), (a3), and (a6).

During the soaking step, one part of the injected heat is conducted to the inner deposit to dissociate the methane hydrate, while another part diffuses to the area far away from the well to be absorbed by the quartz sand and the outside surroundings through the boundary, resulting in the temperature decrease around the well (Figures 13(a4) and (b4)). It can be seen from Figures 13(a5) and (b5) that the temperatures in the vessel decline obviously during the production stage, and the thermal effect range shrinks due to (i) the endothermic reaction of the hydrate dissociation under depressurization and (ii) the cooling effect of the cold fluid flow from the undissociated zone in the vicinity of the boundary to the well. The temperature decreases to lower than $30^{\circ} \mathrm{C}$ at the end of the eighth huff and puff cycle (Figure 13(b5)).

4.4. Hydrate Dissociation Rate and Spatial Distribution of $S_{\mathrm{H}}$. Figure 14 shows the comparison of the

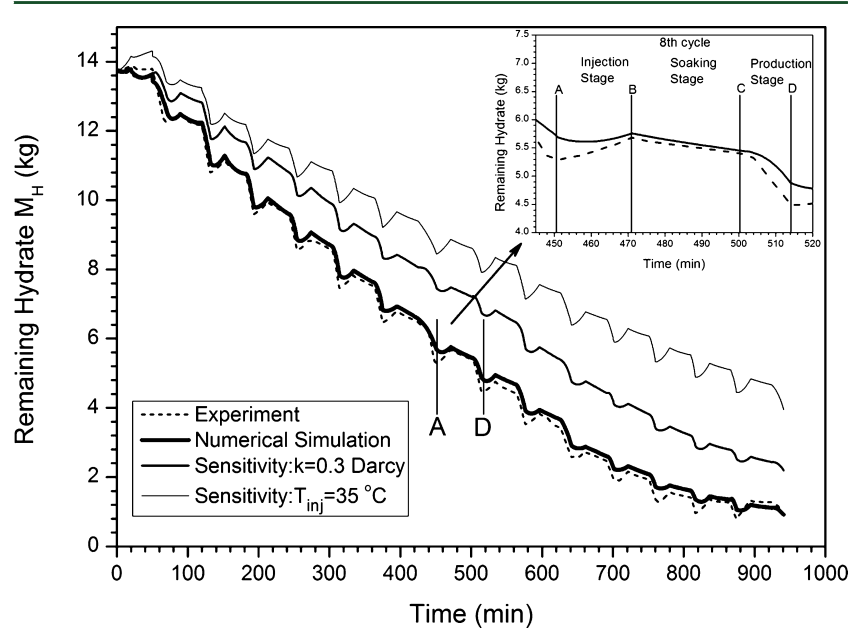

Figure 14. Comparison of the experimental and numerical simulation results of the remaining undissociated hydrate $M_{\mathrm{H}}$ over time in the PHS and its sensitivities to $k$ and $T_{\text {inj }}$ of the numerical simulation.

experimental and numerical simulation results of the remaining undissociated hydrate $M_{\mathrm{H}}$ over time in the PHS. In order to calculate the remaining mass of the three phases (gas, water, and hydrate) in the vessel, we assume that the water and the sand grains are incompressible, and the effective pore volume in the PHS do not change during the whole experiment. Then the mass of the remaining hydrate with time in the PHS is determined through the temperature and pressure measurements and the mass balance calculations using the PengRobinson equation. ${ }^{35}$ The initial mass of the hydrate in the PHS is about $13.6 \mathrm{~kg}$ for both of the experiment and the numerical simulation.

As shown in Figure 14, both the experimental and numerical simulation results indicate that the hydrate in the PHS is dissociated gradually during the entire production process and secondary hydrate formation exists in each huff and puff cycle in the injection stage. As a typical example, the remaining hydrate of the eighth cycle $(A-D)$ is shown in the partial enlarged plot of Figure 14. After the hot water is injected into the PHS from the central vertical well, the gas and water in the vicinity of the well are gradually driven away from the well to the inner deposit, resulting in the increase of the system pressure, which has already been discussed in Figure 7. As the temperature in the area adjacent to the boundary is lower than that in the thermal effect range discussed above (Figure 13), the secondary hydrate begins to form when the pressure increases to be higher than the equilibrium pressure under the mass injection, resulting in an increase of the hydrate in the PHS shown in Figure 14. After ceasing the hot water injection stage, the dissociation process is dominant, and there is gas releasing from hydrate dissociation. During the production stage of the eighth cycle $(\mathrm{C}-\mathrm{D})$, the hydrate dissociation rate becomes faster under the depressurization effect, and the total mass of the dissociated hydrate in the production stage is more than that in the soaking stage, which implies that depressurization rather than thermal stimulation is dominant for the hydrate dissociation. ${ }^{18}$ The diminishing downtrend of the remaining hydrate indicates that the hydrate dissociation rate decreases over time. This is because the injected water is restricted in the vicinity of the well, and the conduction as the main heat transfer pattern in the PHS has very limited efficiency. After 15 huff and puff cycles, the remaining hydrate is about $0.92 \mathrm{~kg}$, which means that $93.3 \%$ of the hydrate has been dissociated.

Figure 15 shows the evolution of the spatial distribution of $S_{\mathrm{H}}$ over time during the hydrate dissociation. The selected three time points are the end of the injection stages of the fourth, the eighth, and the 12th huff and puff cycles, respectively. Generally, the whole PHS is divided into the hydrate dissociated zone and the undissociated zone by an irregular dissociation interface, and this interface expands gradually toward the hydrate body away from the well, which confirms that the hydrate dissociation is an analog of a moving boundary ablation process. $^{36}$ As shown in Figure 15, the hydrate undissociated zone is in accordance with the low- $T$ area shown in Figure 13. During the injection stage, when the released gas is driven away from the well toward the undissociated area (close to the top and bottom surfaces as well as the cylindrical boundary) by the injected water, secondary hydrate is formed under favorable pressure and temperature conditions in this area, and the hydrate saturation rises to about 0.40 , which is much higher than the initial value of 0.292 . On the other hand, the distributions in Figure 15 show that the remaining hydrate is mainly distributed in the area far away from the well, so the hydrate dissociation mainly occurs in this area where the injected hot water could not be involved in most of the huff and puff cycles. During the late huff and puff process, the dissociation interface near the cylindrical boundary gradually disappears, while that in the top and bottom corners of the PHS still exists after the entire production process. This is because they are far away from the injection well, and most of the injected heat is mainly transferred to the outside surroundings through the boundaries other than to the hydrate regions.

4.5. Sensitivity to $k$ and $T_{\text {inj. }}$. In this study, we investigate into the sensitivity of gas production to the intrinsic permeability $k$ and the temperature of the injected hot water $T_{\text {inj }}$ through numerical simulation. The case described above is regarded as the Reference Case. Figures 7, 9, 10, 11, 12, and 14 show, respectively, the dependences of $P, V_{\mathrm{P}}, V_{\mathrm{W}}, R_{\mathrm{GW}}, \eta$, and $M_{\mathrm{H}}$ over time in the PHS on $k$ and $T_{\text {inj. }}$.

When the intrinsic permeability $k$ is decreased from 3.0 to 0.3 Darcy, the well pressure increases to a higher level during the injection and soaking periods in each huff and puff cycle comparing with the Reference Case (Figure 7) when the effective permeabilities $k_{\text {eff }}$ of gas and water are both decreased. 


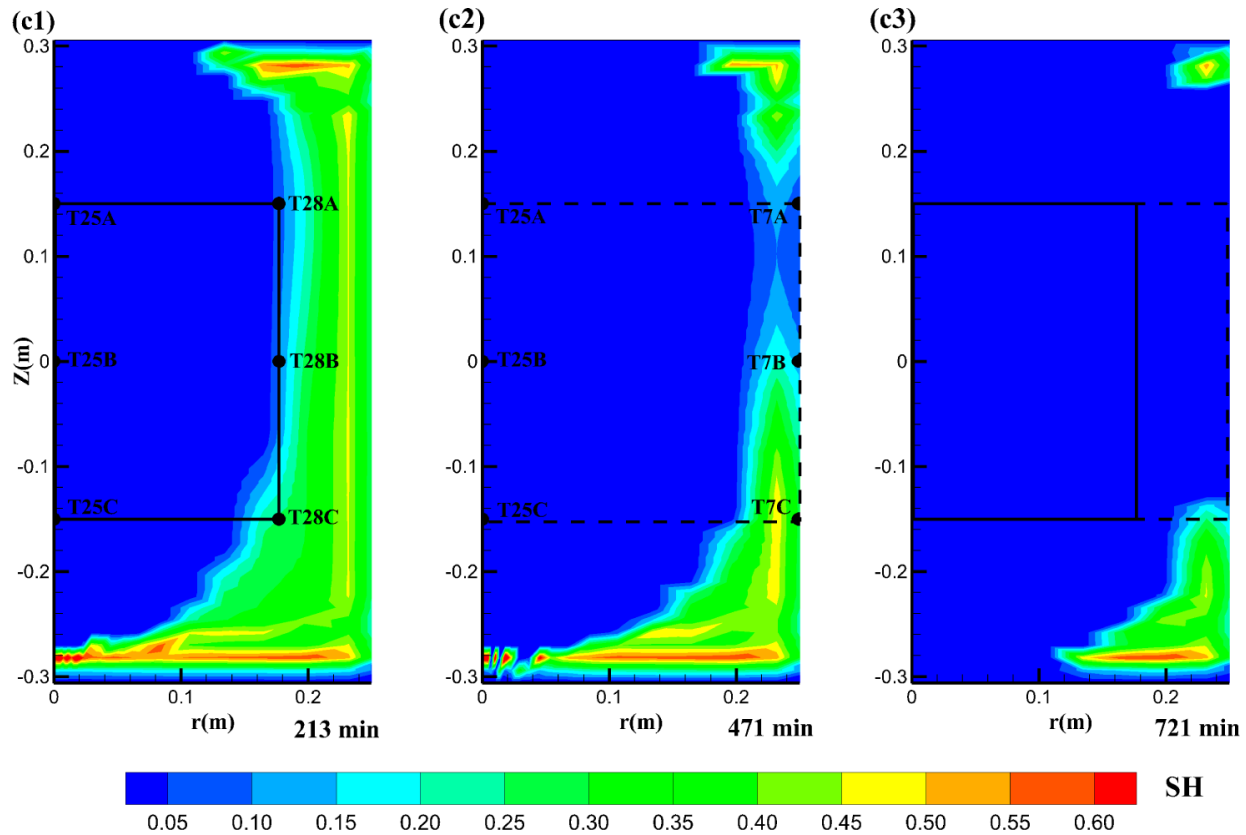

Figure 15. Numerical simulation results of the spatial distribution of $S_{\mathrm{H}}$ over time during hydrate dissociation in the PHS.

There is obvious decline of $V_{\mathrm{P}}$ with a decrease of $k$ (Figure 9), while $V_{\mathrm{W}}$ (Figure 10) nearly keeps the same with the Reference Case, which means that the gas production performance is more favorable with a higher $k$ and the water production is manageable using the huff and puff method. Meanwhile, both the gas-to-water ratio $R_{\mathrm{GW}}$ and the energy efficiency $\eta$ decrease under the condition of $k=0.3 \mathrm{D}$, as shown in Figures 11 and 12. Besides, the hydrate dissociation rate slows down when the injected hot water could not soak into the inner deposit effectively due to the decreased $k_{\text {eff }}$ (Figure 14). Generally, the gas production is favored by a high intrinsic permeability $k$ of the hydrate deposit.

When the temperature of the injected water is reduced from 85 to $35{ }^{\circ} \mathrm{C}$, the pressure rises to lower levels than the Reference Case during the injection and soaking stages (Figure 7). This is because there is less gas released from hydrate dissociation when the injected heat is decreased. In addition, there is obvious decline of $V_{\mathrm{P}}$ comparing with the Reference Case (Figure 9), which indicates that the lower the temperature of the injected hot water is, the less heat it can provide for hydrate dissociation in the injection stage and the less gas released from hydrate. However, the cumulative water produced in each cycle still remains nearly the same with the Reference Case and the case of $k=0.3 \mathrm{D}$ (Figure 10). So the gas-to-water ratio is decreased from about 50.0 to 38.0 with the temperature decline of the injected water (Figure 11). Figure 12 shows that the energy efficiency increases by about 2.5 times under the condition of $T_{\text {inj }}=35^{\circ} \mathrm{C}$ as the heat provided to the system is dramatically reduced. So a lower injection temperature will be more profitable, and it is not necessary to heat the water to an extremely high temperature level from this point of view. As shown in Figure 14, the hydrate dissociation rate is decreased obviously during the whole simulation period when the injection temperature is reduced to $35{ }^{\circ} \mathrm{C}$, which proves that the injected heat plays an important role in the huff and puff hydrate dissociation process. On the other hand, the amount of secondary hydrate formed in the injection stage is more than that of the Reference Case, which is caused by the lower heat transfer rate from the injection well to the inner hydrate deposit.

\section{CONCLUSIONS}

In this work, we investigate by means of experimental and numerical simulation the gas production behavior of methane hydrate in porous media in the novel Pilot-Scale Hydrate Simulator (PHS). The huff and puff method is employed for hydrate dissociation in a single vertical well placed at the axis of the PHS. Each huff and puff cycle consists of three stages: the injection stage, the soaking stage, and the production stage. Based on the results of this study, the following conclusions are drawn from the experimental and numerical simulation.

In the Reference Case $\left(T_{\text {inj }}=85^{\circ} \mathrm{C}, Q_{\text {inj }}=0.2 \mathrm{~L} / \mathrm{min}, t_{\text {inj }}=\right.$ $20 \mathrm{~min}$ ), both the experimental and numerical simulation results show a regular fluctuation of the system pressure during the huff and puff process, and the increment speed in the soaking stage is much lower than that in the injection stage. Because of the high porosity and permeability of the sediment, the pressures at different locations in the PHS have little discrepancy and any of them can be taken as the system pressure. With the constant hot water injection rate, it shows that the injected hot water has an approximately cylindrical moving front around the well, and it is mainly restricted in the area of $r<0.08 \mathrm{~m}$. The conduction performs as the main heat transfer pattern in the PHS for hydrate dissociation. The highest temperature (more than $80^{\circ} \mathrm{C}$ ) is observed in the vicinity of the injection well at the end of the injection stage, and the high- $T$ region gradually enlarges in different injection stages with more heat absorbed by the quartz sand and the external surroundings.

The gas production rate maintains approximately stable in a relatively long period, while it decreases over time with the decrease of the hydrate dissociation rate in the later production stage. As the absolute criterion of gas production performance, the average gas production rate $Q_{a v g}$ is about $2.89 \mathrm{~L} / \mathrm{min}$ in the end. During the entire huff and puff process, the average water production rate is about $3.8 \mathrm{~L} /$ cycle, which is lower than the 
hot water injection rate. The mass of the water produced in each cycle has little difference and is manageable when using the huff and puff method. The long-term gas-to-water ratio $R_{\mathrm{GW}}$ is more than $49.5 \mathrm{ST} \mathrm{m}{ }^{3}$ of $\mathrm{CH}_{4} / \mathrm{m}^{3}$ of $\mathrm{H}_{2} \mathrm{O}$, and the energy efficiency is about 6.5 at the end of the experiment, indicating the effectiveness and economic efficiency of the huff and puff method from the relative criterion point of view. The hydrate is dissociated gradually during the entire production process, and secondary hydrate formation exists in each huff and puff cycle in the injection stage.

The numerical analysis of sensitivity to $k$ indicates that the deposit with higher intrinsic permeability will show better gas production performance as the flow conditions become more favorable for the released gas. A decrease of the intrinsic permeability will result in a declined hydrate dissociation rate when the hot water could not soak into the hydrate deposit effectively due to the decreased $k_{\text {eff. }}$ Generally, a higher $k$ is associated with higher gas production and more beneficial $R_{\mathrm{GW}}$ and $\eta$, while the water production rate changes little during the huff and puff process. In addition, the numerical analysis of sensitivity to $T_{\text {inj }}$ indicates that the hydrate dissociation, the gas production rate, and the gas-to-water ratio can be enhanced by raising the temperature of the injected hot water, while it has little effect on the water production rate in each huff and puff cycle. However, higher $T_{\text {inj }}$ will results in lower energy efficiency as more heat is needed for heating the injected water. Lower injection temperature may be more profitable using the huff and puff method.

The numerical simulation results of the pressure profiles, the gas and water production, the gas-to-water ratio, the energy efficiency, the spatial distribution of $T$, and the remaining hydrate in the PHS all agree well with the experiment, which demonstrates that the model can describe the hydrate formation and dissociation behaviors well in porous media during the huff and puff process. So it is concluded that our developed model can predict the gas production performance from complex porous media.

\section{AUTHOR INFORMATION}

\section{Corresponding Author}

*Phone/Fax: +86 20 87057037. E-mail: lixs@ms.giec.ac.cn.

\section{Notes}

The authors declare no competing financial interest.

\section{ACKNOWLEDGMENTS}

This work was supported by National Natural Science Foundation of China (Grants 51225603, 51076155, and 51004089), Key Arrangement Programs of the Chinese Academy of Sciences (Grants KGZD-EW-301-2) and Natural Science Foundation of Guangdong Province (Grants 10451007006006174), which are gratefully acknowledged.

\section{NOMENCLATURE}

$d=$ diameter of the PHS $(\mathrm{m})$

$h=$ height of the PHS (m)

$k=$ intrinsic permeability $\left(\mathrm{m}^{2}\right)$

$k_{\text {eff }}=$ effective permeability $\left(\mathrm{m}^{2}\right)$

$k_{\mathrm{rA}}=$ aqueous relative permeability $\left(\mathrm{m}^{2}\right)$

$k_{\mathrm{rG}}=$ gas relative permeability $\left(\mathrm{m}^{2}\right)$

$k_{\Theta \mathrm{C}}=$ thermal conductivity $(\mathrm{W} /(\mathrm{m} \cdot \mathrm{K}))$

$k_{\Theta \mathrm{RD}}=$ thermal conductivity of dry porous medium (W/ $(\mathrm{m} \cdot \mathrm{K}))$
$k_{\Theta \mathrm{RW}}=$ thermal conductivity of fully saturated porous medium $(\mathrm{W} /(\mathrm{m} \cdot \mathrm{K}))$

$k_{\Theta \mathrm{I}}=$ thermal conductivity of ice $(\mathrm{W} /(\mathrm{m} \cdot \mathrm{K}))$

$M_{\mathrm{H}}=$ remaining hydrate mass $(\mathrm{kg})$

$P=$ pressure $(\mathrm{MPa})$

$Q_{\text {avg }}=$ average gas production rate $(\mathrm{L} / \mathrm{min})$

$Q_{\text {inj }}=$ hot water injection rate $(\mathrm{L} / \mathrm{min})$

$Q_{\text {pro }}=$ mass production rate $(\mathrm{kg} / \mathrm{s})$

$R_{\mathrm{GW}}=$ cumulative gas to water production ratio $\left(\mathrm{ST} \mathrm{m}^{3}\right.$ of $\mathrm{CH}_{4} / \mathrm{m}^{3}$ of $\mathrm{H}_{2} \mathrm{O}$ )

$S_{\mathrm{A}}=$ initial aqueous saturation, volume

$S_{\mathrm{G}}=$ initial gas saturation, volume

$S_{\mathrm{H}}=$ initial hydrate saturation, volume

$r=$ radius

$r, z=$ cylindrical coordinates $(\mathrm{m})$

$T=$ temperature $\left({ }^{\circ} \mathrm{C}\right)$

$t=$ time $(\mathrm{min})$

$t_{\text {inj }}=$ duration of the hot water injection (min)

$T_{\text {inj }}=$ initial temperature of the hot water $\left({ }^{\circ} \mathrm{C}\right)$

$V=$ volume of the PHS (L)

$V_{\mathrm{P}}=$ cumulative volume of the produced $\mathrm{CH}_{4}(\mathrm{~L})$

$V_{\mathrm{W}}=$ cumulative volume of the produced water $(\mathrm{L})$

$X_{\mathrm{S}}=$ salinity

$\Delta r=$ discretization along the $r$-axis $(\mathrm{m})$

$\Delta z=$ discretization along the $z$-axis (m)

$\phi=$ porosity

$\lambda=$ van Genuchten exponent - Table 1

\section{Subcripts and Superscripts}

$0=$ denotes initial state

$\mathrm{A}=$ aqueous phase

$\mathrm{B}=$ boundary

cap = capillary

$\mathrm{G}=$ gas phase

$\mathrm{H}=$ solid hydrate phase

$\mathrm{I}=$ ice phase

irA = irreducible aqueous phase

irG = irreducible gas

$n=$ permeability reduction exponent - Table 1

$n_{G}=$ gas permeability reduction exponent - Table 1

$\mathrm{S}=$ salinity

$\mathrm{W}=$ well

\section{REFERENCES}

(1) Sloan, E. D.; Koh, C. A. Clathrate Hydrates of Natural Gases, 3rd ed.; CRC Press: Boca Raton, FL, 2008.

(2) Collett, T. S. Gas hydrates as a future energy resource. Geotimes 2004, 49 (11), 24-27.

(3) Moridis, G. J.; Silpngarmlert, S.; Reagan, M. T.; Collett, T.; Zhang, K. Gas production from a cold, stratigraphically-bounded gas hydrate deposit at the Mount Elbert Gas Hydrate Stratigraphic Test Well, Alaska North Slope: Implications of uncertainties. Mar. Pet. Geol. 2011, 28 (2), 517-534.

(4) Li, G.; Moridis, G. J.; Zhang, K.; Li, X. S. Evaluation of gas production potential from marine gas hydrate deposits in Shenhu Area of South China Sea. Energy Fuels 2010, 24, 6018-6033.

(5) Ahmadi, G.; Ji, C. A.; Smith, D. H. Production of natural gas from methane hydrate by a constant downhole pressure well. Energy Convers. Manage. 2007, 48 (7), 2053-2068.

(6) Moridis, G. J.; Reagan, M. T.; Boyle, K. L.; Zhang, K. Evaluation of the gas production potential of some particularly challenging types of oceanic hydrate deposits. Transp. Porous Media 2011, 90 (1), 269299.

(7) Tang, L. G.; Xiao, R.; Huang, C.; Feng, Z. P.; Fan, S. S. Experimental investigation of production behavior of gas hydrate 
under thermal stimulation in unconsolidated sediment. Energy Fuels 2005, 19 (6), 2402-2407.

(8) Li, G.; Li, X. S.; Tang, L. G.; Li, Q. P. Control Mechanisms for Methane Hydrate Production by Thermal Stimulation. In The 6th International Conference on Gas Hydrate; Vancouver, British Columbia, Canada, 2008; Paper 5783.

(9) Yang, X.; Sun, C. Y.; Yuan, Q.; Ma, P. C.; Chen, G. J. Experimental study on gas production from methane hydrate-bearing sand by hot-water cyclic injection. Energy Fuels 2010, 24, 5912-5920.

(10) Pang, W. X.; Xu, W. Y.; Sun, C. Y.; Zhang, C. L.; Chen, G. J. Methane hydrate dissociation experiment in a middle-sized quiescent reactor using thermal method. Fuel 2009, 88 (3), 497-503.

(11) Li, D. L.; Liang, D. Q.; Fan, S. S.; Li, X. S.; Tang, L. G.; Huang, N. S. In situ hydrate dissociation using microwave heating: Preliminary study. Energy Convers. Manage. 2008, 49 (8), 2207-2213.

(12) Kawamura, T.; Yamamoto, Y.; Ohtake, M.; Sakamoto, Y.; Komai, T.; Haneda, H. Experimental study on dissociation of hydrate core sample accelerated by thermodynamic inhibitors for gas recovery from natural gas hydrate. In The 5th International Conference on Gas Hydrate; Trondheim, Norway, 2005; pp 3023-3028.

(13) Li, G.; Li, X. S; Tang, L. G; Zhang, Y. Experimental investigation of production behavior of methane hydrate under ethylene glycol stimulation in unconsolidated sediment. Energy Fuels 2007, 21 (6), 3388-3393.

(14) Yuan, Q.; Sun, C. Y.; Yang, X.; Ma, P. C.; Ma, Z. W.; Li, Q. P.; Chen, G. J. Gas production from methane-hydrate-bearing sands by ethylene glycol injection using a three-dimensional reactor. Energy Fuels 2011, 25 (7), 3108-3115.

(15) Ota, M.; Morohashi, K.; Abe, Y.; Watanabe, M.; Smith, R. L.; Inomata, $\mathrm{H}$. Replacement of $\mathrm{CH}_{4}$ in the hydrate by use of liquid $\mathrm{CO}_{2}$. Energy Convers. Manage. 2005, 46 (11-12), 1680-1691.

(16) Zhou, X. T.; Fan, S. S.; Liang, D. Q.; Du, J. W. Replacement of methane from quartz sand-bearing hydrate with carbon dioxide-inwater emulsion. Energy Fuels 2008, 22 (3), 1759-1764.

(17) Moridis, G. J.; Reagan, M. T. Strategies for Gas Production From Oceanic Class 3 Hydrate Accumulations. In The Offshore Technology Conference; Houston, Texas, 2007; Paper OTC 18865.

(18) Li, X. S.; Yang, B.; Li, G.; Li, B.; Zhang, Y.; Chen, Z. Y. Experimental study on gas production from methane hydrate in porous media by huff and puff method in pilot-scale hydrate simulator. Fuel 2012, 94 (1), 486-494.

(19) Sayegh, S. G.; Maini, B. B. Laboratory evaluation of the $\mathrm{CO}_{2}$ huff-n-puff process for heavy oil-reservoirs. J. Can. Pet. Technol. 1984, 23 (3), 29-36.

(20) Al-Wadhahi, M.; Boukadi, F. H.; Al-Bemani, A.; Al-Maamari, R.; Al-Hadrami, H. Huff 'n puff to revaporize liquid dropout in an Omani gas field. J. Pet. Sci. Eng. 2007, 55 (1-2), 67-73.

(21) Li, G.; Moridis, G. J.; Zhang, K.; Li, X. S. The use of huff and puff method in a single horizontal well in gas production from marine gas hydrate deposits in the Shenhu Area of South China Sea. J. Pet. Sci. Eng. 2011, 77 (1), 49-68.

(22) Li, X. S.; Li, B.; Li, G.; Yang, B. Numerical simulation of gas production potential from permafrost hydrate deposits by huff and puff method in a single horizontal well in Qilian Mountain, Qinghai province. Energy 2012, 40 (1), 59-75.

(23) Yang, X.; Sun, C. Y.; Su, K. H.; Yuan, Q.; Li, Q. P.; Chen, G. J. A three-dimensional study on the formation and dissociation of methane hydrate in porous sediment by depressurization. Energy Convers. Manage. 2012, 56, 1-7.

(24) Li, X. S.; Zhang, Y.; Li, G.; Chen, Z. Y.; Wu, H. J. Experimental investigation into the production behavior of methane hydrate in porous sediment by depressurization with a novel three-dimensional cubic hydrate simulator. Energy Fuels 2011, 25 (10), 4497-4505.

(25) Li, G.; Li, X. S.; Wang, Y.; Zhang, Y. Production behavior of methane hydrate in porous media using huff and puff method in a novel three-dimensional simulator. Energy 2011, 36 (5), 3170-3178.

(26) Li, X. S.; Wang, Y.; Li, G.; Zhang, Y.; Chen, Z. Y. Experimental investigation into methane hydrate decomposition during three- dimensional thermal huff and puff. Energy Fuels 2011, 25 (4), $1650-1658$

(27) Moridis, G. J.; Kowalsky, M. B.; Pruess, K. TOUGH+HYDRATE v1.1 User's Manual: A Code for the Simulation of System Behavior in Hydrate-Bearing Geologic Media; Lawrence Berkeley National Laboratory: Berkeley, CA, 2009.

(28) Li, X. S.; Yang, B.; Zhang, Y.; Li, G.; Duan, L. P.; Wang, Y.; Chen, Z. Y.; Huang, N. S.; Wu, H. J. Experimental investigation into gas production from methane hydrate in sediment by depressurization in a novel pilot-scale hydrate simulator. Appl. Energy 2012, 93, 722732.

(29) Moridis, G. J.; Reagan, M. T.; Kim, S. J.; Seol, Y.; Zhang, K. Evaluation of the gas production potential of marine hydrate deposits in the Ulleung Basin of the Korean East Sea. SPE J. 2009, 14 (4), 759781.

(30) Li, G.; Li, X. S.; Chen, Q.; Chen, Z. Y. Numerical simulation of gas production from gas hydrate zone in Shenhu Area, South China Sea. Acta Chim. Sin. 2010, 68 (11), 1083-1092.

(31) Moridis, G. J.; Reagan, M. T.; Boyle, K. L.; Zhang, K. Evaluation of the Gas Production Potential of Challenging Hydrate Deposits. In TOUGH Symposium; Lawrence Berkeley National Laboratory: Berkeley, CA, 2009.

(32) Li, X. S.; Zhang, Y.; Li, G.; Chen, Z. Y.; Yan, K. F.; Li, Q. P. Gas hydrate equilibrium dissociation conditions in porous media using two thermodynamic approaches. J. Chem. Thermodyn. 2008, 40 (9), 14641474.

(33) Zhang, K.; Moridis, G. J.; Wu, Y. S.; Pruess, K. A Domain Decomposition Approach for Large-Scale Simulations of Flow Processes in Hydrate-Bearing Geologic Media. In The 6th International Conference on Gas Hydrate; Vancouver, British Columbia, Canada, 2008; Paper 5480.

(34) Moridis, G. J.; Collett, T. S.; Dallimore, S. R.; Satoh, T.; Hancock, S.; Weatherill, B. Numerical studies of gas production from several $\mathrm{CH}_{4}$ hydrate zones at the Mallik site, Mackenzie Delta, Canada. J. Pet. Sci. Eng. 2004, 43 (3-4), 219-238.

(35) Li, G.; Li, B.; Li, X. S.; Zhang, Y.; Wang, Y. Experimental and numerical studies on gas production from methane hydrate in porous media by depressurization in pilot-scale hydrate simulator. Energy Fuels 2012, 26 (10), 6300-6310.

(36) Yousif, M. H.; Abass, H. H.; Selim, M. S.; Sloan, E. D. Experimental and theoretical investigation of methane-gas-hydrate dissociation in porous media. SPE Reservoir Eng. 1991, 6 (4), 69-76.

(37) Moridis, G. J.; Seol, Y.; Kneafsey, T. J. Studies of reaction kinetics of methane hydrate dissociation in porous media. In The 5th International Conference on Gas Hydrate; Trondheim, Norway, 2005; pp 1004-1014.

(38) van Genuchten, M. T. A Closed-form equation for predicting the hydraulic conductivity of unsaturated soils. Soil Sci. Soc. Am. J. 1980, 44, 892-898. 